\title{
80 PEDAGÓGICA
}

NO. 10 - ENERO/DICIEMBRE DE 2009
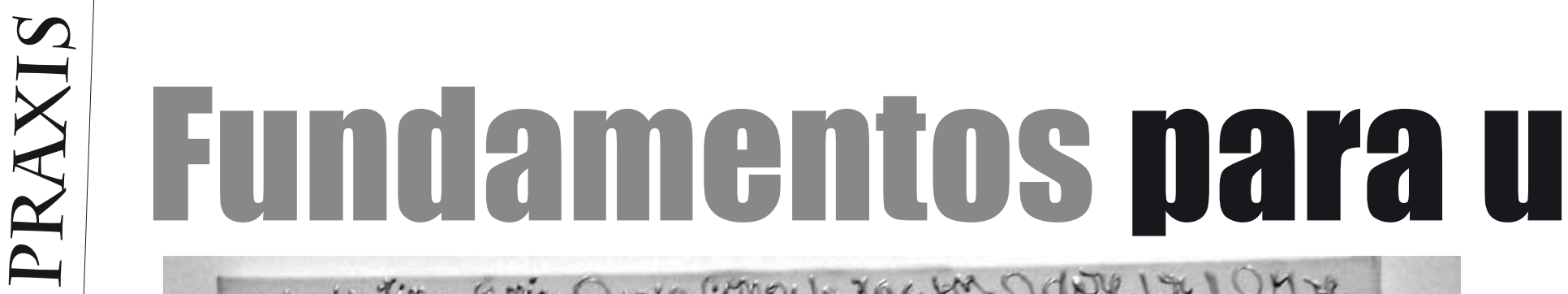

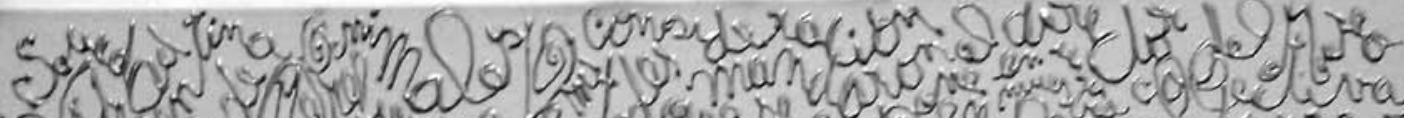

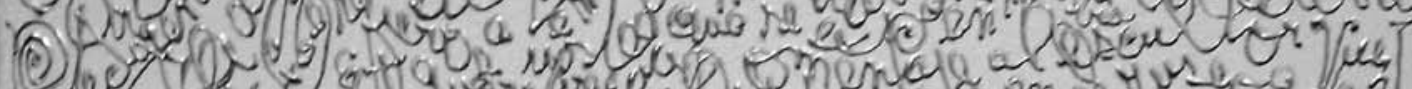

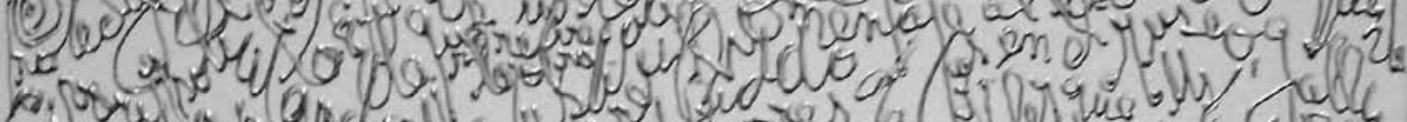

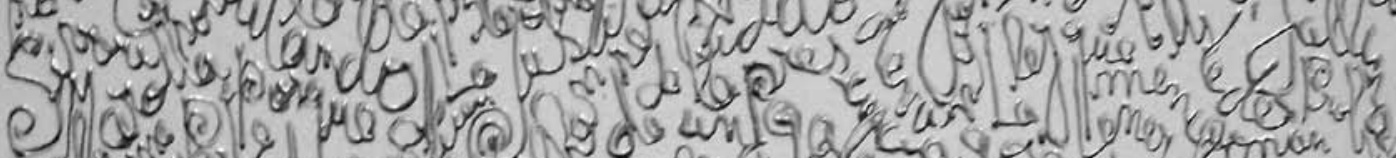

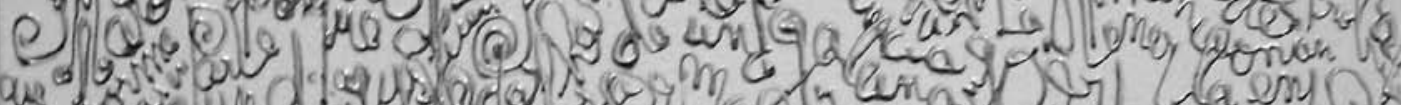
qu 35 . wh a - 1 do

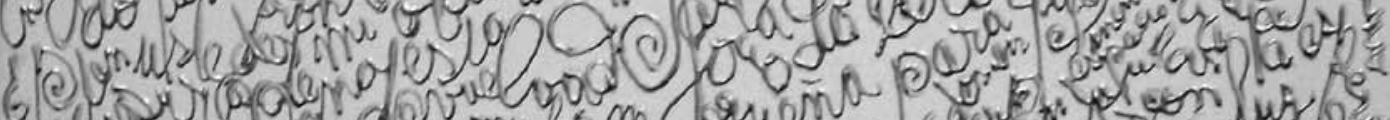

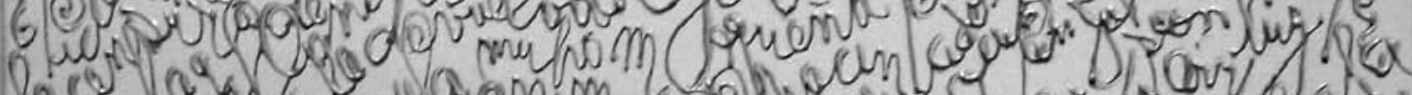

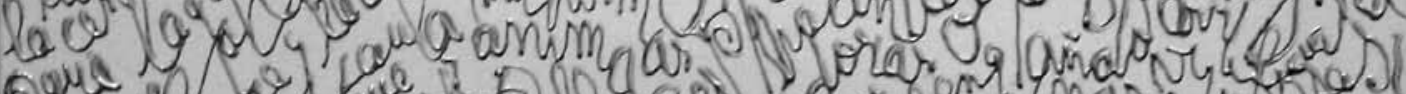

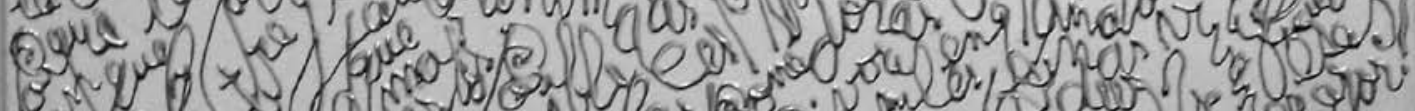

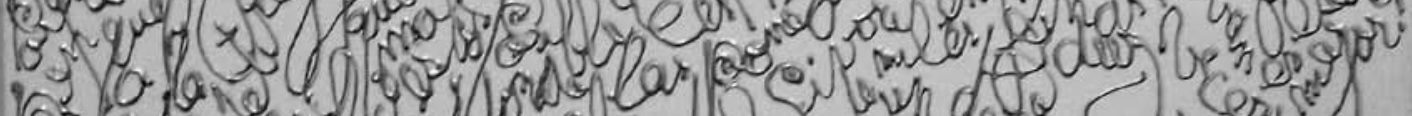
(e) a gar a

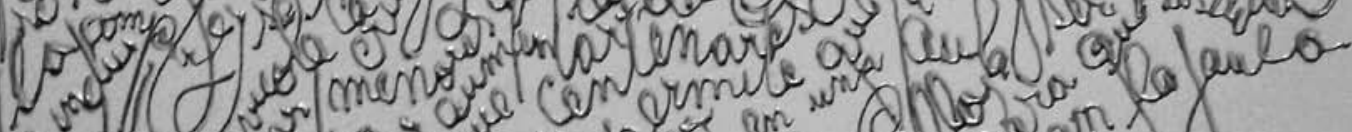

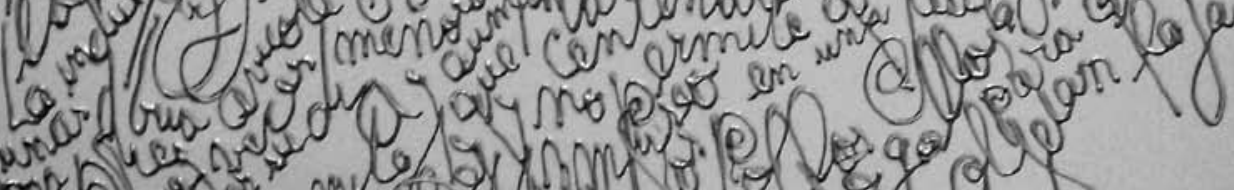

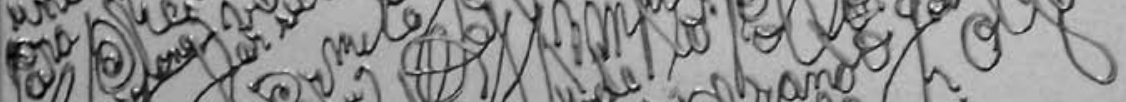

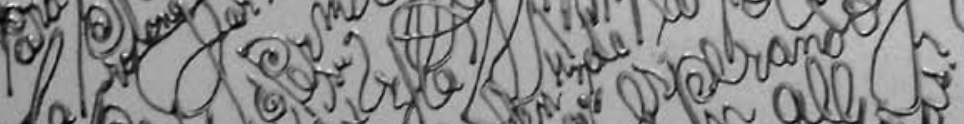

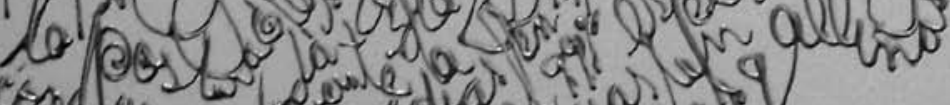

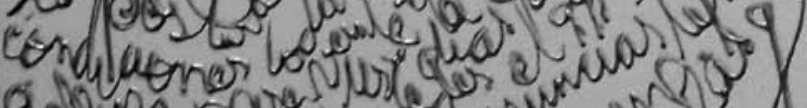

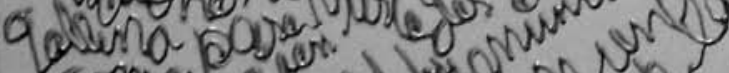

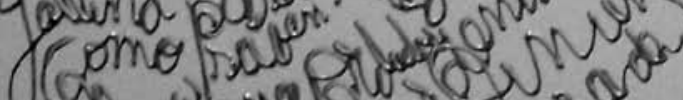

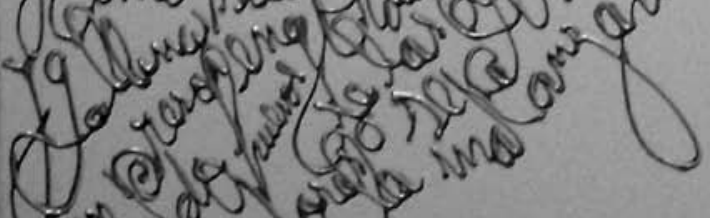

T.8.

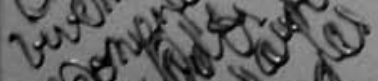

8 Cojo a sos

(a) $100.5 \%$

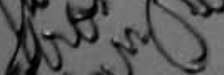

afg

is 


\section{na

\section{William L. PeRdomo VANEGAS}

Docente- investigador de la facultad de educación de Uniminuto. wperdomo@uniminuto.edu

\section{RES U M E N}

Este trabajo es el producto de una investigación en torno a los estudios literarios, desarrollada al interior de la Facultad de Educación, específicamente en el departamento de Humanidades y Lengua Castellana. Este informe está constituido por tres partes, en la primera se fundamenta conceptualmente la investigación en literatura desde un enfoque científico; la segunda parte hace un recorrido histórico sobre los aspectos más relevantes en la teoría y la crítica literarias; por último se sustenta una propuesta en torno a los estudios literarios en el contexto colombiano.

Palabras clave: Estudios literarios, investigación científica, crítica y teoría literarias, contexto colombiano.

\section{A B S T R A C T}

This work is the product of research into literary studies, developed within the Bachelor of Arts Education, specifically in the Humanidades y Lengua Castellana department. This report consists of three parts, the first part is based on literature research conceptually from a scientific approach; the second part is a historical survey on the most important aspects in literary criticism and theory; finally a proposal is based around literary studies in the Colombian context.

Key words: Literary Studies, scientific research, literary criticism and theory, Colombian context. 


\section{FUNDAMENTACIÓN EPISTEMOLÓGICA}

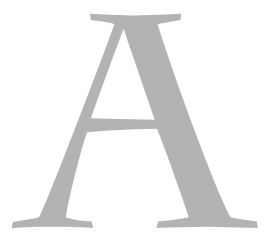

ctualmente la definición de literatura se relaciona con la cultura y la sociedad y, al mismo tiempo, designa tres acciones específicas: 1) la práctica de creación verbal, que involucra la producción de obras escritas por ciertos individuos que buscan valorar la sociedad en la que están inmersos; 2) la actividad de investigación y conocimiento de dicha práctica verbal, que se define como la labor del crítico o estudioso del proceso de producción de las distintas manifestaciones literarias; y 3) por último, la práctica institucional educativa que socialmente permite producir y conservar los productos de la creación verbal considerados como componentes esenciales del patrimonio cultural. Aquí también se vincula lo que se denomina didáctica de la literatura.

De acuerdo con estas premisas, se puede afirmar que la literatura, entendida como estudios literarios, se define como "una disciplina científica orientada hacia la descripción y comprensión de los discursos denominados literarios dentro de las humanidades" (Huaman, 2004, p. 84). Por lo tanto, su objetivo es "precisar las condiciones de funcionamiento y producción de sentido de las manifestaciones literarias, su incidencia en una formación social y su importancia en la esfera cultural" (p. 96). Es evidente que es un objetivo de estudio complejo que involucra a los propios observadores y que convoca a una discusión en torno a su método de investigación, en el que se concentran todas las posibilidades y dificultades para su autonomía epistemológica.

\section{SemblanZa DE lOS ESTUdios literarios Del Siglo XX}

Aunque las reflexiones sobre la importancia de los estudios literarios tiene sus inicios con los griegos, no es sino hasta principios del siglo XX que se reconoce la especificidad de los fundamentos del conocimiento en los estudios literarios, momento en el que comienza su proceso de constitución como campo disciplinario. Sólo en las últimas décadas se ha logrado un estatuto científico reconocible. No obstante, también se debe reconocer que este proceso sólo describe algunas prácticas de estudio e investigación.

Gracias a los desarrollos de la lingüística moderna, que promovía nuevos enfoques en torno a las ciencias del lenguaje, los estudios literarios se distanciaron de la explicación causal y determinista del historicismo para afirmar la descripción y el análisis de los mecanismos discursivos y, al mismo tiempo, enfocar su estudio en el sistema de producción de sentido de la obra literaria. Por último, en las últimas tres décadas del siglo, la hegemonía de la estructura y lo sincrónico en las investigaciones literarias cederán paso a los modelos del uso literario del lenguaje en el contexto de una comunicación socio-cultural y simbólica.

A continuación, se presentará una semblanza sobre el desarrollo de los estudios literarios en el siglo XX.

\section{FORMALISMO RUSO}

El formalismo ruso es uno de los movimientos de teoría de la literatura y crítica literaria más importantes del siglo XX. Surgió en Rusia entre 1914 y los años 1930. Se divide principalmente en dos escuelas, la escuela de Moscú liderada por Viktor Shklovsky y la escuela de Praga liderada por Roman Jakobson.

Se formó con estudiantes que se reunían en la OPOYAZ, sociedad para el estudio de la Lengua Poética, que duró de 1914 a 1923. Advenida la Revolución Rusa esta estética fue condenada formal y categóricamente en 1930 por su falta de contenido social; esta interdicción obligó a sus componentes al exilio y a relegar sus obras a la oscuridad. En esta época los trabajos de los formalistas rusos se transformaron en una rareza bibliográfica. Pero, mientras, algunas apariciones en Europa provocaron el interés del estructuralismo francés, que utilizó largamente el Formalismo Ruso para formular algunas de sus teorías. 
El formalismo ruso modificó las posturas respecto a los conceptos de arte, literatura y texto en el transcurso del siglo XX y abrió el camino de la nueva crítica angloamericana (New criticism) e, incluso, a la crítica marxista. Según Raman Selden (1993), los formalistas rusos se interesaban en establecer un método científico (formal) que pudiera estudiar seriamente la literatura. Sin embargo, esta postura fue modificada sustancialmente en épocas posteriores cuando los formalistas se interesaron en el desarrollo de modelos e hipótesis que "permitieran explicar cómo los mecanismos literarios producen efectos estéticos y cómo lo literario se distingue y se relaciona con lo extraliterario".

\section{ESTRUCTURALISMO: UNA DESCRIPCIÓN TEXTUAL IDEAL}

El estructuralismo desechó simultáneamente el objeto real y el sujeto humano. Este movimiento doble define el proyecto estructuralista. La obra ni se refiere a un objeto ni es expresión de un sujeto individual; ambos son descartados, y sólo queda entre ellos, en el aire que las separa, un sistema de reglas. Por lo tanto si sólo se piensa que un texto, que una lectura se puede reducir solamente a la descripción de este sistema propiamente dicho, se está nada más lejos, pues, el estructuralismo se transforma así en "antihumanista", vale decir, se convierte en un objeto cualquiera, que no necesita más que la sola aplicación de unas reglas o método para saber de él, sin embargo, lo que se logra saber no es más que el funcionamiento interno de éste y no su conexión con el todo del proceso y no solamente del producto.

El estructuralismo podía estudiar detalladamente ese producto, pero se negó a estudiar las condiciones materiales de su elaboración, pues esto podría significar que se rendía al mito que acepta un "origen”.
No hubo muchos estructuralistas a quienes preocupase la forma en que realmente se consumía el producto; ni lo que en verdad sucede cuando la gente lee obras de literatura; ni el papel que esas obras desempeñan en el conjunto de las relaciones sociales. Por último, si los críticos tradicionales constituían una élite espiritual, los estructuralistas parecían integrar una élite científica, de toda clase de conocimientos esotéricos muy alejados del lector "común y corriente".

\section{Hermenéutica, Fenomenología y Teoría de la RECEPCIÓN}

Según Eagleton (1998), la Hermenéutica Fenomenológica ha de ser estudiada mediante tres factores: la Fenomenología, la Hermenéutica y la Teoría de la Recepción. Para el primer elemento establece una base teórica en Husserl, luego para el segundo en Heidegger, Gadamer y Hirsch, y para la tercera, revisa a los pilares de la recepción: Ingarden, Iser y Fish. Con estos autores entonces sienta los orígenes de la Teoría de la Recepción y, por consiguiente, se obtiene una visión historicista bastante clara, pero no suficiente, pues ha olvidado revisar por ejemplo a Schleiermacher, fundador de la hermenéutica general, antecesor de Heidegger y sostiene al respecto, afirmando explícitamente, la unidad entre ambas disciplinas. Tampoco vincula la herencia rabínica ni la poética sanscrita, las que usaría precisamente Todorov para fortalecer su estrategia de la interpretación. Como tampoco revisa antecedentes fundamentales para la Teoría de la Recepción: La lingüística, y la sociológica.

En el nuevo método de crítica literaria participan principalmente tres corrientes: una lingüística, otra hermenéutica y la sociológica. Para la primera corriente, López señala la influencia de la Escuela de Praga,

\section{EN EL NUEVO MÉTODO DE CRÍTICA LITERARIA PARTICIPAN PRINCIPALMENTE TRES CORRIENTES: UNA LINGÜÍSTICA, OTRA HERMENÉUTICA Y LA SOCIOLÓGICA.}


especialmente Mukarovsky y Vodicka. El primero, distingue dos aspectos en la obra literaria: por un lado, su aspecto material de artefacto invariable; $y$ semántico; su aspecto de objeto estético, variable en la conciencia colectiva, según las experiencias literarias de ésta. Dice Mukarovsky: "en la historia y teoría de la literatura y del arte, por ejemplo, no sólo se debe tener en cuenta la forma interna artística y su desarrollo como una estructura, sino también la relación de esta estructura con otros fenómenos, sobre todo aquellos de contenido psicológico y social... Todo cambio en la estructura artística es motivado de alguna manera desde exterior..." sin embargo, la relación entre arte y sociedad no es mecánico-casual. Ni siquiera el contacto propiamente dicho entre arte y sociedad es inmediato, sino que se realiza, como ya se ha dicho, por mediación del público. Y para el segundo - dice Berta López que también Vodicka pretende establecer las relaciones entre la obra literaria y la realidad, entre el objeto y su receptor. Las tareas de la crítica literaria según el análisis de la obra literaria en su contexto histórico (normas y valores de su época, etc.) y su eco en épocas posteriores.

Para la segunda corriente, la hermenéutica, no hay gran diferencia con el análisis que hace Eagleton. Para la tercera, López revisa los estudios de Schüking y Escarpit y por otra línea a Lukács, refiriendo de esta manera, entonces, a la corriente sociológica. Schüking por su parte, aporta estímulos precursores a través de su obra "El gusto literario" (1931). Investigó la relación entre la obra literaria y determinados grupos sociales, la relación entre cambios socio-históricos y los respectivos cambios literarios sobre el fondo de las normas estéticas, dependientes de ciertos grupos sociales. Escarpit en Sociología de la Literatura, (1958) y Sartre y su modelo de la literatura “engagée”, no sólo analiza la función de la literatura en la sociedad, sino también el problema de establecer el significado de la obra literaria: "Un pacto de generosidad" entre autor y lector como proceso correlativo a la escritura - dice Sartre -.Manuel Jofré en Teoría Literaria y Semiótica (1990) también aduce: al respecto, ha dicho Sartre que se le deja al lector con todo por hacer, y sin embargo, ya todo ha sido hecho; la obra existe solamente en el nivel de las habilidades del lector, y cuando él lee y crea, él sabe que siempre puede ir más allá en su lectura, y que siempre podrá crear más profundamente; y esta es la razón por la cual la obra aparece ante él tan inexhaustiva e inpenetrable como un objeto. Para Sartre, entonces, el lector es co-autor, co-productor de significado.

Finalmente, se sobreentiende la importancia crítica socialista de Lukács y sus discípulos, y de la obra " Pour una sciologie du roman” (1964) de Lucien Goldmann, su idea de relacionar "la forma novelesca misma y la estructura del medio social en cuyo interior se ha desarrollado", la homología entre vida social y obra literaria.

\section{Sociocrítica}

Bajo el nombre de sociocrítica se agrupa una "serie de investigaciones que intentan profundizar en el conocimiento de la literatura como hecho social a partir de la peculiar y compleja realidad textual" (Linares Alés, 1996, p. 7). La sociocrítica es un estudio social y textual al mismo tiempo. Se trata de una sociología crítica que aspira a ser una sociología del texto. Intenta restituirle al texto de los formalistas su condición social en cuanto específica producción estética, no como reflejo de tal o cual realidad: la sociocrítica lee lo social presente en el texto. Se trata de ver cómo se inscriben en el texto las condiciones sociales indisociables de la textualidad. "El objetivo de la sociocrítica es mostrar que toda creación artística es también prácticas social y por ende producción ideológica, por ser un proceso estético y no tanto un vehículo de enunciados" (Duchet, 1979, p. 3). En este sentido, la sociocrítica es una especie de sociogénesis, una sociología de la escritura, una sociología del texto y una sociología del lector. El texto literario no es tanto la expresión de una ideología (su puesta en palabra) como su puesta en escena, su exhibición. Su objeto está centrado en el sujeto, la ideología y las instituciones. Los principales representantes de la sociocrítica son: 
Edmond Cros, Claude Duche, Pierre Zima, Antonio Gómez Moriana.

Después de este recorrido a través de la historia de la teoría literaria, se puede afirmar que, el proceso de transformación de las concepciones en torno a la ciencia y a las prácticas sociales y científicas de fines del siglo XX contribuyó a que los estudios literarios se reconocieran como una disciplina científica. La superación de la concepción tradicional de la ciencia y el surgimiento de una nueva postura epistemológica han permitido que la investigación literaria se relacione con diversos campos del conocimiento de manera interdisciplinaria y transdisciplinaria. Esta nueva epistemología aportó tres aspectos significativos para la una visión más amplia de la ciencia: (1) la superación de la ruptura en la relación sujeto/ objeto, para verla más como una interacción en la que el observador desempeña un papel más activo; (2) la correspondencia de la ciencia con una evidencia empírica y; (3) la temporalidad de los procesos y los fenómenos.

\section{$\mathrm{Al}$ respecto Miguel Ángel Huamán afirma que}

Tres aspectos de esta nueva epistemología han servido de bisagras para esta participación: la superación de la separación sujeto/objeto, el descrédito de lo regular o reversible y el retorno de la flecha del tiempo. En el primero de estos puntos, se ha tornado cada vez más evidente que la intermediación de los signos o lenguajes y la imposibilidad del observador de evitar su incidencia en lo observado hacen de toda explicación una interpretación que varía sólo en su grado o modalidad. En el segundo punto se pone en evidencia que la visión tradicional del universo que la ciencia clásica ofrecía, que desterraba lo contingente o azaroso, era más una proyección humana que una evidencia empírica, y respondía a una matemática determinista y no probabilística. En el tercer punto se enfatiza la necesaria temporalidad de los procesos y fenómenos, su irreversibilidad y aleatoriedad, con lo que las tendencias nomotéticas en la ciencia ceden su lugar a lo histórico. Todo lo indicado ha significado que lo que constituía las debilidades de nuestras disciplinas humanas para una óptica positivista y determinista del conocimiento, se conviertan en fortalezas. (2004, p. 7).

Esta nueva epistemología permite trascender sobre la errada idea de una diferencia entre las ciencias naturales y sociales o humanas; igualmente, al sustentar una visión crítica del mundo, en la que éste se define como un sistema amplio, abierto, inestable y caótico, establece las bases para una revaloración de los estudios literarios y su papel crítico. Por consiguiente, en el marco de esta nueva epistemología, la investigación literaria se fundamenta como actividad científica.

\section{MetOdología de INVESTIGACIÓN EN LOS ESTUdiOS LITERARIOS}

La investigación literaria implica responder a uno o varios interrogantes sobre un discurso o práctica textual específica. Este tipo de investigación no requiere de un muestreo estadístico, un trabajo de campo o experimentos en laboratorios para validar sus datos, ya que fenomenológicamente basta con estudiar un "solo" caso. La investigación literaria se remite a un solo hecho, caso o dato en su rasgo particular y general. Por lo tanto, los resultados de la investigación literaria pertenecen al campo de las ciencias humanas y sociales, debido a que el objeto de estudio no es independiente de la conciencia del investigador. En el campo de las ciencias humanas y sociales el sujeto y el objeto se implican mutuamente puesto que los fenómenos que son materia de su indagación no existen al margen de la conciencia del observador ni su ocurrencia como fenómeno es ajena a la sociedad o cultura. En ese sentido, no se pueden focalizar los estudios literarios como si se trataran de eventos o hechos naturales que ocurren aparentemente en forma espontánea, sin que medien nuestra intención y voluntad.

El objeto de estudio de la literatura no se define como fenómeno por su causalidad y regularidad sino por su naturaleza de sentido y su irregularidad. Debido a estas características, la investigación literaria se ubica en el 
grupo de actividades científicas que emergen como alternativa al enfoque positivista y cuantitativo; como lo es el enfoque cualitativo. La investigación cualitativa se caracteriza por ser multimetódica y porque implican un enfoque interpretativo. De ahí la afinidad con la investigación literaria y el porqué ésta pertenece al campo de los métodos cualitativos. En otras palabras, no existe un único método para la lectura de un texto ni mucho menos para el análisis del mismo y toda la operación comprensiva consiste en ostentar una interpretación.

Partiendo de algunos aportes de diversos trabajos en metodología de la investigación, la investigación cualitativa se define como un enfoque fenomenológico, etnográfico o interpretativo que se caracteriza porque el investigador al plantear un problema no establece un proceso perfectamente definido como en un laboratorio sino que primero utiliza dicha formulación para descubrir y refinar las preguntas de la investigación. En lugar de partir de una teoría en particular, observa y examina un determinado fenómeno o hecho para asumir la teoría adecuada, que es denominada teoría fundamentada; de modo que es el objeto el que impone la concepción más idónea para su tratamiento (Hernández-Fernández-Baptista, 2006; Esterberg, 2002; Grinnell, 1997). Igualmente, algunos investigadores concuerdan en que "las investigaciones cualitativas se fundamentan más en un proceso inductivo (explorar y describir), y luego generar perspectivas teóricas. Van de lo particular a lo general” (Hernández-Fernández-Baptista, 2006).

En ese sentido, en la medida que gran parte de los estudios cualitativos no proceden por inducción ni deducción no establecen ni se prueban hipótesis. Estas se generan en el proceso y se refinan conforme a la información o son un resultado del estudio. Las investigaciones de este tipo se basan en métodos de acopio de datos no estandarizados, cuya precisión acerca el método de observación al de la lectura crítica: "La recolección de los datos consiste en obtener las perspectivas y puntos de vista de los participantes (sus emociones, experiencias, significados y otros aspectos subjetivos). También resultan de interés las interacciones entre individuos, grupos y colectividades" (HernándezFernández-Baptista, 2006).

Los estudios literarios pertenecen al enfoque de investigación cualitativo por la propia naturaleza de su proceso. La lectura crítica de un texto, para el análisis del discurso respectivo, es una técnica de observación y recolección de datos no estructurada que como indagación científica tiene el rasgo esencial de ser flexible. Su dinámica transita entre la precisión de eventos y su interpretación, la formulación de preguntas y respuestas constantes que logran un entramado preciso dentro de una teoría que emerge como necesidad de la reconstrucción del proceso de significación o de generación de sentido de un discurso determinado; siendo así

La investigación cualitativa se fundamenta en una perspectiva interpretativa centrada en el entendimiento del significado de las acciones de seres vivos, principalmente los humanos y sus instituciones (busca interpretar lo que va captando activamente) [...] Postula que la realidad se define a través de las interpretaciones de los participantes en la investigación respecto de sus propias realidades. De este modo convergen varias realidades, por lo menos la de los participantes, la del investigador y la que se produce mediante la interacción de todos los actores. Además son realidades que van modificándose conforme transcurre el estudio. Estas realidades son las fuentes de datos. (Hernández-Fernández-Baptista, p. 8).

Por lo tanto, el enfoque cualitativo puede definirse "como un conjunto de prácticas interpretativas que hacen al mundo visible, lo transforman y lo convierten en una serie de representaciones en forma de observaciones, anotaciones, grabaciones y documentos. Es naturalista (porque estudia los objetos y seres vivos en sus contextos o ambientes naturales) e interpretativo (pues intenta encontrar sentido a los fenómenos en términos de los significados que las personas les otorguen)” (Hernández-Fernández- 

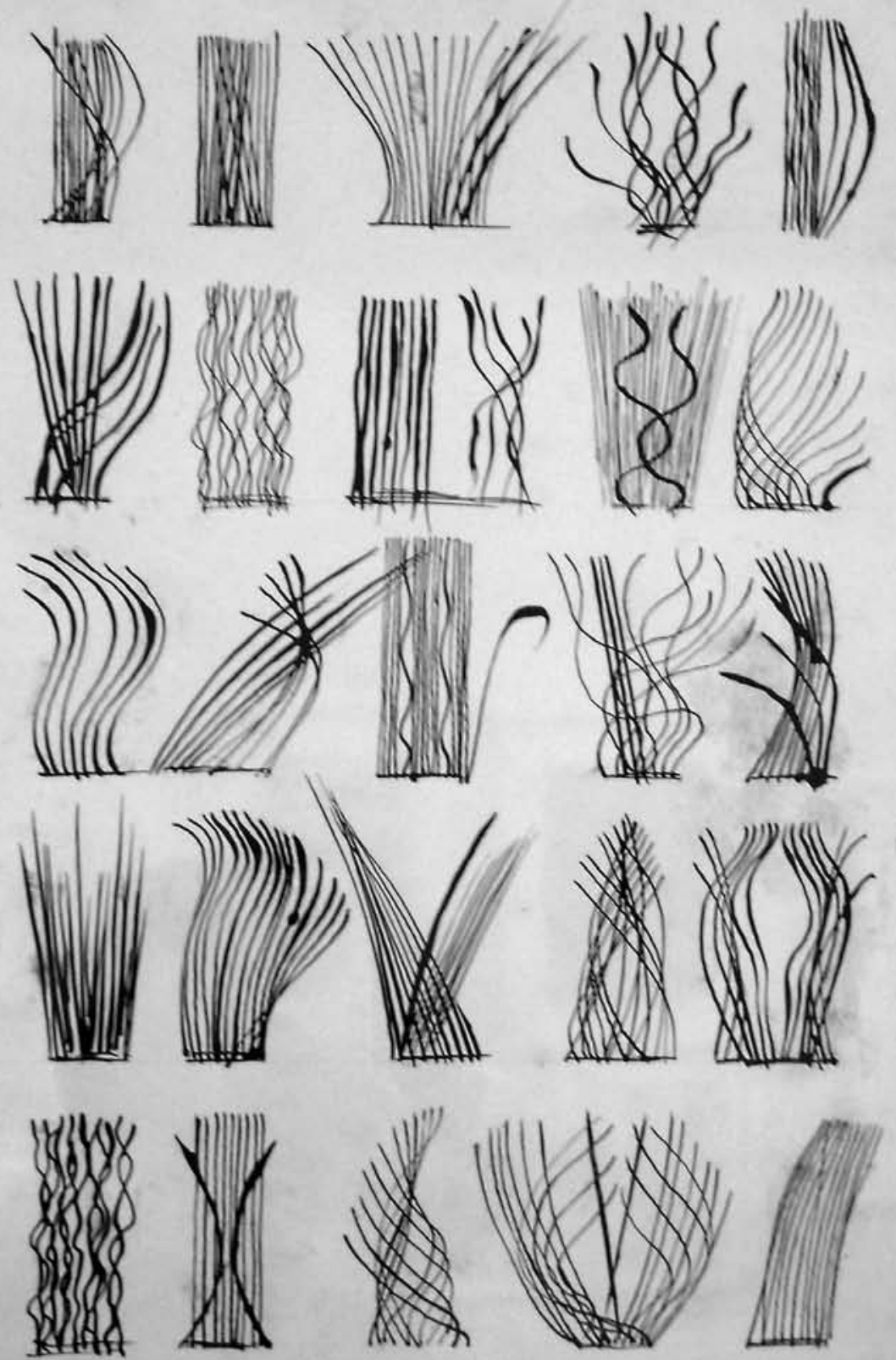

VochBuLAR:O 
Baptista, p. 9). Para Roberto Hernández, Carlos Fernández y Pilar Batista los criterios constitutivos de un método cualitativo son:

Poseer una teoría fundamentada: la teoría es un marco de referencia que no se fundamenta en estudios anteriores, sino que se genera o construye a partir de los datos empíricos obtenidos y analizados. Es decir, no se parte de una teoría particular que luego se enfrenta con lo empírico a través de la observación, sino que en la recopilación de datos desarrolla una teoría coherente con la información que va descubriendo.

Actualizar un patrón cultural: la metodología cualitativa implica una variedad de marcos de interpretación que poseen como común denominador el partir de las premisas de una cultura o sistema social. Estas visiones del mundo o concepciones se encuentran en el centro del estudio de lo cualitativo, como modelos culturales flexibles que constituyen marcos de referencia construidos por el inconsciente, lo transmitido por otros y por la vivencia personal y sirven de espacio en donde se actualizan las teorías.

Recolección de datos influida por las experiencias: la experiencia o vivencia del investigador influye en el acopio de información y las prioridades del observador inciden en el proceso. La importancia de los instrumentos estandarizados, estructurados y predeterminados es mínima.

La realidad se modifica por el proceso de conocimiento: la realidad cambia por las observaciones y la recolección de datos porque describe, comprende e interpreta los fenómenos a través de las percepciones y significados de los participantes.

Las hipótesis se generan durante o al final del estudio: no prueban hipótesis sino que se generan durante el proceso y van refinándose conforme se recaban más datos o son resultado del estudio.

En las ciencias humanas la observación es el método fundamental de recopilación de datos. Para Hyman (1972) la historia de las humanidades como ciencia ha sido el desarrollo de procedimientos y medios instrumentales que eliminan o corrigen gradualmente las desviaciones o las distorsiones al efectuar las observaciones. Obviamente no se trata de una observación superficial sino científica; es decir, tan objetiva como sea posible y que se diferencia del conocimiento ordinario.

Los estudios literarios como integrantes de las ciencias humanas son disciplinas de la observación. En el análisis del discurso, la observación es la lectura que le posibilita al investigador literario advertir los hechos o datos del texto, los mismos que le permiten la comprensión cabal de su producción de sentido. La lectura crítica constituye el fundamento de la observación analítica en la disciplina interpretativa y busca la comprobación del fenómeno que se tiene frente a la vista, con la única preocupación de evitar y prever los errores de observación que pueden alterar la correcta comprensión del mismo.

Por consiguiente, la investigación literaria como proyecto y proceso es una actividad que pretende propiciar el debate en torno a la naturaleza de este tipo de conocimiento y su contribución junto con otras

UN ENFOQUE EN LITERATURA LES OTORGARÁ A LOS ESTUDIANTES HERRAMIENTAS COGNITIVAS PARA TRABAJAR EN TORNO AL ANÁLISIS LITERARIO Y SOCIOCRÍTICO FRENTE A LOS GÉNEROS LITERARIOS. 
disciplinas humanas al surgimiento de una nueva epistemología en el conocimiento científico. Asimismo, la importancia de los estudios literarios radica en el enriquecimiento de una cultura de diálogo, una identidad nacional y una matriz solidaria de crítica a la sociedad posmoderna en crisis.

\section{PARA UNA PROPUESTA DE INVESTIGACIÓN EN ESTUdiOS LITERARIOS}

En vista de la preocupación que existe por los trabajos de grado realizados al interior del departamento de Humanidades y Lengua Castellana, se ha querido ofrecer una alternativa para aquellos estudiantes interesados en la literatura como opción de grado, en este sentido, la propuesta del enfoque en estudios literarios en el contexto social colombiano tiene como objetivo entender la literatura como un amplio y complejo fenómeno social y cultural; por lo tanto este enfoque busca que los trabajos de grado desarrollados desde esta perspectiva deben dar cuenta de una reflexión social de un contexto social colombiano. Objetivo que tiene sus cimientos en los espacios académicos de Teoría y crítica literaria, Literatura y sociedad y Literatura colombiana.

Este enfoque les permite a los estudiantes de la licenciatura en Educación Básica con Énfasis en Humanidades y Lengua castellana aproximarse a las teorías, métodos, manuales y prácticas de la enseñanza - aprendizaje de la literatura, igualmente, identificar la funcionalidad de los materiales y métodos literarios en la enseñanza de la lengua española. En este enfoque, los estudiantes podrán optar por la escritura literaria como producto final del trabajo de grado, así como el desarrollo de didácticas para la motivación de la escritura creativa y la aproximación al análisis literario desde una perspectiva social. Por otra parte, un enfoque en literatura les otorgará a los estudiantes herramientas cognitivas para trabajar en torno al análisis literario y sociocrítico frente a los géneros literarios.
1. Didáctica de la literatura.

2. Análisis del discurso literario colombiano.

3. Creación literaria.

\section{DesARROLlo DE DidÁcticAS DE LA LITERATURA (2)}

Esta propuesta, inmersa en énfasis de literatura, tiene como objetivo desarrollar didácticas en torno al proceso de enseñanza-aprendizaje de la literatura en lengua española. La propuesta de didáctica de la literatura como trabajo de grado en la licenciatura se define como un ejercicio teórico-práctica qué, en un contexto específico de enseñanza-aprendizaje, orienta, a partir de diversos procesos comunicativos, el aprendizaje de lo literario y, en consecuencia, la construcción del conocimiento. Desde este punto de vista, cuatro aspectos la definen:

1) Es teórica, en cuanto intenta explicar qué cosa es la enseñanza.

2) Es práctica, porque define cómo se enseña.

3) Es teórico-práctica, ya que parte de la realidad, la observa, la analiza y aporta soluciones a su problemática.

4) Es crítica, en la medida en que al descubrir los problemas reales ofrece soluciones tanto con relación al contexto escolar como a los sujetos que intervienen en la acción pedagógica: el maestro y el alumno.

En este sentido, los estudiantes que opten por esta propuesta deberán dar cuenta de una sistematización de alguna experiencia educativa, en la que se dé cuenta de desarrollo de alguna(s) didáctica(s) de la literatura que evidencie al hombre como un objeto de conocimiento y de educación. Siendo así, debemos situar dos dimensiones de la didáctica de la literatura en las que se pueden desarrollar un trabajo de grado:

a) Dimensión de orden ideológico-socio-educativo: esta dimensión se enfoca en los posibles cuestionamientos e inquietudes sobre lo que es necesario 
al desarrollar un proceso de comunicación, cuestionamiento como: ¿qué ciudadano se va a forma dentro del aula de clase?, ¿para qué circunstancias socio-históricas se está preparando?, ¿qué tipo de conocimiento de la disciplina será pertinente ofrecerle?, ¿qué habilidades cognitivas del estudiante se deben favorecer para una mejor aproximación al aprendizaje de la literatura como goce estético y como creatividad? En otras palabras, se sitúa al estudiante como centro de la educación, de la realidad y del conocimiento. Esta ubicación es histórica, dialéctica y dinámica en la medida que tanto éste como la educación van cambiando de manera permanente.

\section{b) Dimensión de orden teórico-práctico: dimensión} que se relaciona con un nivel praxeológico de la enseñanza. Lo teórico se define como la concepción implícita de la disciplina, su valoración y los modos de tratamiento del texto literario. Lo práctico expresa la concepción de lo que se puede lograr por la vía de la enseñanza de la lectura literaria. Es decir, cómo organizamos una didáctica desde la selección de los contenidos, el planteamiento de los objetivos, las actividades y las formas de evaluación y, a la vez, su interrelación con el maestro y el alumno. La finalidad de esta propuesta no es sólo demostrar cómo se aprende y enseña literatura, sino plantear el contexto en el que se da el acto comunicativo para distinguir y clasificar los elementos que entran en juego en la transmisión y en la adquisición del saber. Desde esta perspectiva, el texto como objeto literario y su lectura constituyen el núcleo central del proceso de enseñanza-aprendizaje. Por medio del aprendizaje, tanto de los contenidos teóricos como de los estéticos, es posible el acercamiento al conocimiento, así como el desarrollo de capacidades y actitudes sobre el mundo, la vida y el hombre.

En resumen, estas dos dimensiones se logran a partir de la concepción que cada docente (o futuro docente) posee de la disciplina, de su valoración - formadora de la conciencia individual y social, instrumento de goce y de placer- y de la organización de las propuestas metodológicas (guías) para enfocar la lectura literaria. Este planteamiento nos remite a que cada uno de los trabajos realizados en el marco de este énfasis responda dos preguntas: ¿cuál debe ser el eje de constitución de la disciplina (didáctica de la literatura)?, ¿qué tipo de formación se tratará de ofrecer al estudiante? Por lo tanto, atiende tanto a la relación comunicativa básica entre el maestro y el alumno, como a la relación particular texto-lector-alumno.

\section{ANÁLISIS DEL DISCURSO LITERARIO COLOMBIANO}

A través de los años la sociología de la literatura se ha consolidado como un método de estudio en torno a las obras literarias de los llamados trascendentes, es decir, aquellos que analizan las obras en virtud de una clave interpretativa que está más allá de la configuración estructural del texto. En concreto, la sociología de la literatura establece conclusiones que parten de la consideración de la literatura como realidad, fenómeno social, en tanto que relaciona las obras literarias y sus creadores, la sociedad y el momento histórico en que nacen, y la orientación política que las inspira.

De igual manera, la sociocrítica, que, aunque en origen no es sinónimo de sociología de la literatura, ha terminado con el tiempo por referirse, aunque de forma más restringida, al mismo ámbito de estudio. La sociocrítica fue una disciplina surgida dentro de la Nouvelle Critique francesa, y buscaba distanciarse de la estética marxista tradicional a través del uso de principios metodológicos propios de la Semiótica, la Neorretórica y la Hermenéutica. En este sentido, la sociocrítica se concentra exclusivamente en las estructuras textuales y su relación con la sociedad (en sentido lato), a diferencia de la sociología de la literatura que aborda también todo el proceso de producción, distribución, reedición y recepción de las obras.

En este orden de ideas, desde un enfoque de la literatura de la sociología sociocrítico, los estudiantes de la licenciatura tendrán la posibilidad de reflexionar sobre algunos procesos sociales que influyeron en un 
contexto determinado, particularmente en Colombia. Siendo así esta propuesta tiene como objetivo desarrollar trabajos de grado que permitan mostrar que toda creación literaria es también una reflexión y una práctica social y, por ende, una producción enmarcada en una ideología, debido a que se manifiesta como un proceso estético y no como un relación de enunciados. En este enfoque los estudiantes podrán llevar a cabo el análisis de una obra literaria colombiana del siglo XX mediante la aplicación de los conceptos planteados por los siguientes autores:

\section{NotAs}

* Esta trabajo se puede considerar como el marco teórico de la investigación realizada en el departamento, el cual se constituye en como fundamento para la línea de investigación de estudios literarios en el contexto latinoamericano.

1 Esta propuesta es retomada de los planteamientos de Ana Ester Eguinoa.

\section{REFERENCIAS BIBLIOGRÁFICAS}

Anguera, María Teresa (1997). Metodología de la observación en ciencia humanas. Madrid: Cátedra.

Arnau Gras, Jaime (1978). Métodos de investigación en ciencias humanas, Barcelona: Omega.

Barthes, Roland (1985). La aventura semiológica. Barcelona: Piados, 1990. y otros (1974). Análisis estructural del relato. Buenos Aires: Tiempo Contemporáneo.

Beristáin, H. (1984). Análisis estructural del relato literario. México: UNAM.

Beuchot, Mauricio y Ricoeur, Paul (1989). Hermenéutica, lenguaje e inconsciente. México: Universidad Autónoma de Puebla.

Eagleton Terry (1994). Una Introducción a la Teoría Literaria. Bogotá: Fondo de Cultura Económica.
Echeverría, Javier (1999). Introducción a la metodología de la ciencia. La filosofía de la ciencia en el siglo XX. Madrid: Cátedra.

Eco, Umberto (1995). Semiótica y filosofía del lenguaje. Barcelona: Lumen.

Fox, David (1981). El proceso de investigación en educación. Pamplona: Universidad de Navarra.

Hernández Sampieri, Roberto; Fernández-Collado, Carlos y Pilar Baptista Lucio (2006). Metodología de la investigación. México: Mcgraw Hill.

Huamán, Miguel Ángel (2004). "La formación literaria y la nueva pedagogía”. Escritura y pensamiento, 14, Lima: UNMSM, 2004.

Hurtado de Barrera, Jacqueline (2002). Formación de investigadores. Retos y alternativas, Bogotá: Magisterio.

Mejía Mejía, Elías (2005). Metodología de la investigación científica, Lima, UNMSM.

Paun de García, Susan (2004). Manual práctico de investigación literaria. Cómo preparar informes, trabajos de investigación, tesis y tesinas. Madrid: Castalia.

Rodríguez Gómez, Gregorio; Gil Flores, Javier y Eduardo García Jiménez (1999). Metodología de la investigación cualitativa, Málaga: Aljibe.

Todorov, T. (1974). "Las categorías del relato literario". Análisis estructural del relato. Buenos Aires: Tiempo Contemporáneo.

(1973). Gramática del Decamerón. Madrid: Taller de E.J. Betancor.

Walker, Melissa (2000). Cómo escribir trabajos de investigación. Barcelona: Gedisa.

Trottier, D. (1993). Juego textual y profanación. San José: EUCR.

Culler, J. (1978). La poética estructuralista. Barcelona: Anagrama.

Chen Sham, J. (1991) "Proposiciones para una teoría de la lectura sociocrítica”. Káñina, XV, 1-2 enero-diciembre. 